Continuous glucose monitoring and $\mathrm{HbA} 1 \mathrm{c}$ in the evaluation of glucose metabolism in children at high risk for type 1 diabetes mellitus

\author{
Helminen, Olli
}

2016-10

Helminen , O , Pokka , T , Tossavainen , P , llonen , J , Knip , M \& Veijola , R 2016 , ' Continuous glucose monitoring and $\mathrm{HbA} 1 \mathrm{c}$ in the evaluation of glucose metabolism in children at high risk for type 1 diabetes mellitus ' , Diabetes Research and Clinical Practice , vol. 120 , pp. 89-96 . https://doi.org/10.1016/j.diabres.2016.07.027

http://hdl.handle.net/10138/230030

https://doi.org/10.1016/j.diabres.2016.07.027

publishedVersion

Downloaded from Helda, University of Helsinki institutional repository.

This is an electronic reprint of the original article.

This reprint may differ from the original in pagination and typographic detail.

Please cite the original version. 


\title{
Continuous glucose monitoring and HbA1c in the evaluation of glucose metabolism in children at high risk for type 1 diabetes mellitus
}

\author{
Olli Helminen ${ }^{a, *}$, Tytti Pokka ${ }^{a}$, Päivi Tossavainen ${ }^{a}$, Jorma Ilonen ${ }^{b}$, Mikael Knip ${ }^{c, d, e, f}$, \\ Riitta Veijola ${ }^{a}$ \\ ${ }^{a}$ Department of Pediatrics, PEDEGO Research Unit, Medical Research Center, Oulu University Hospital and University of Oulu, Oulu, Finland \\ ${ }^{\mathrm{b}}$ Immunogenetics Laboratory, University of Turku and Turku University Hospital, Turku, Finland \\ ${ }^{\mathrm{c}}$ Tampere Centre for Child Health Research, Tampere University Hospital, Tampere, Finland \\ d Children's Hospital, University of Helsinki and Helsinki University Hospital, Helsinki, Finland \\ ${ }^{\mathrm{e}}$ Research Programs Unit, Diabetes and Obesity, University of Helsinki, Helsinki, Finland \\ ${ }_{\mathrm{f}}^{\mathrm{F}}$ Folkhälsan Research Center, Helsinki, Finland
}

\section{A R T I C L E I N F O}

Article history:

Received 4 May 2016

Received in revised form

3 July 2016

Accepted 30 July 2016

Available online 6 August 2016

\section{Keywords:}

Type 1 diabetes mellitus

Autoantibodies

Glucose intolerance

Self-monitoring

Blood-glucose

Prediabetes

\begin{abstract}
A B S T R A C T
Aims: Continuous glucose monitoring (CGM) parameters, self-monitored blood glucose (SMBG), HbA1c and oral glucose tolerance test (OGTT) were studied during preclinical type 1 diabetes mellitus.

Methods: Ten asymptomatic children with multiple $(\geqslant 2)$ islet autoantibodies (cases) and 10 age and sex-matched autoantibody-negative controls from the Type 1 Diabetes Prediction and Prevention (DIPP) Study were invited to 7-day CGM with Dexcom G4 Platinum Sensor. HbA1c and two daily SMBG values (morning and evening) were analyzed. Five-point OGTTs were performed and carbohydrate intake was assessed by food records. The matched pairs were compared with the paired sample t-test.

Results: The cases showed higher mean values and higher variation in glucose levels during CGM compared to the controls. The time spent $\geqslant 7.8 \mathrm{mmol} / \mathrm{l}$ was $5.8 \%$ in the cases compared to $0.4 \%$ in the controls $(p=0.040)$. Postprandial CGM values were similar except after the dinner $(6.6 \mathrm{mmol} / \mathrm{l}$ in cases vs. $6.1 \mathrm{mmol} / \mathrm{l}$ in controls; $p=0.023)$. When analyzing the SMBG values higher mean level, higher evening levels, as well as higher variation were observed in the cases when compared to the controls. HbA1c was significantly higher in the cases [5.7\% (39 mmol $/ \mathrm{mol})$ vs. $5.3 \%$ ( $34 \mathrm{mmol} / \mathrm{mol}) ; p=0.045]$. No differences were observed in glucose or C-peptide levels during OGTT. Daily carbohydrate intake was slightly higher in the cases (254.2 g vs. $217.7 \mathrm{~g} ; p=0.034$ ).

Conclusions: Glucose levels measured by CGM and SMBG are useful indicators of dysglycemia during preclinical type 1 diabetes mellitus. Increased evening glucose values seem to be common in children with preclinical type 1 diabetes mellitus.
\end{abstract}

(c) 2016 Elsevier Ireland Ltd. All rights reserved.

\footnotetext{
* Corresponding author at: Department of Pediatrics, PEDEGO Research Unit, MRC Oulu, University of Oulu, PO Box 5000, Oulu FIN-90014, Finland. Fax: +358 83155559.
}

E-mail address: olli.helminen@oulu.fi (O. Helminen). http://dx.doi.org/10.1016/j.diabres.2016.07.027 0168-8227/@ 2016 Elsevier Ireland Ltd. All rights reserved. 


\section{Introduction}

Type 1 diabetes mellitus is a chronic autoimmune disease characterized by immune-mediated destruction of the pancreatic $\beta$-cells. The incidence of type 1 diabetes mellitus has been increasing worldwide, with the highest rate observed in Finland [1-3]. The preclinical phase of the disease can be identified through the presence of autoantibodies to pancreatic $\beta$-cell antigens [4]. Confirmed positivity for $\geqslant 2$ biochemical islet autoantibodies provide a cumulative risk of more than $80 \%$ during follow up for 15 years in children with HLA-conferred disease susceptibility [5,6].

The characteristics of glucose metabolism during the preclinical phase of type 1 diabetes mellitus have so far been monitored using oral and intravenous glucose tolerance tests (OGTT and IVGTT, respectively) which show deteriorating glucose tolerance and insulin secretion in high-risk children as the disease progresses [7-11]. It has been previously shown that $\mathrm{HbA1c}$ values start to rise as early as 2 years before the diagnosis of type 1 diabetes mellitus [12], and reported that HbA1c, OGTT and randomly measured plasma glucose values are useful in the prediction of the timing of the diagnosis in high-risk children $[9,12,13]$.

Continuous glucose monitoring (CGM) is becoming more common in patients with clinical type 1 diabetes mellitus to monitor glycemic management. Regular CGM is associated with improved glucose levels, although the benefit seems to depend on target population [14,15]. In preclinical type 1 diabetes mellitus CGM might be helpful in the identification of individuals at high risk for progressing to overt disease in the near future [16-18]. Early identification of children with deteriorating glucose tolerance may prevent acute complications at clinical diagnosis. CGM could also be used to monitor glucose excursions in clinical trials aimed at secondary prevention of type 1 diabetes mellitus [19].

In this study the aim was to characterize the differences in glucose metabolism by using 7-day CGM combined with food records and calibration with self-monitored blood glucose (SMBG), HbA1c and five-point OGTT with glucose and C-peptide analyses in children with increased class II HLA associated genetic risk for type 1 diabetes mellitus and multiple $(\geqslant 2)$ biochemical islet autoantibodies in comparison with age- and sex-matched controls carrying a risk-conferring HLA class II genotype but testing negative for autoantibodies.

\section{Methods}

\subsection{Study design}

The Type 1 Diabetes Prediction and Prevention Study (DIPP) is a Finnish population-based cohort study in which genetically predisposed children are followed since birth for islet autoantibodies [20-22]. The current analysis included 10 children with preclinical type 1 diabetes mellitus (cases) defined as carrying HLA-conferred disease susceptibility and testing positive for at least two positive biochemical autoantibodies (insulin autoantibodies [IAA], GAD antibodies [GADA] or antibodies to the insulinoma-2 associated antigen [IA-2A]), and 10 age- and sex-matched control children with HLAdefined predisposition to type 1 diabetes mellitus but no autoantibodies. Autoantibodies were analyzed as previously described [6]. The age at seroconversion was defined as the age when at least one of the biochemical (IAA, GADA, IA-2A) islet autoantibodies was detected for the first time. The age at positivity for multiple autoantibodies was defined as the time point, when at least two biochemical islet autoantibodies were detected in the same sample. All CGMs were performed between March 2014 and February 2015. The study was approved by the Ethics Committee of the Oulu University Hospital, Oulu, Finland. All families participating in the study provided written informed consent.

\subsection{Continuous glucose monitoring}

Ten children with multiple biochemical islet autoantibodies were invited to continuous glucose monitoring with Dexcom G4 PLATINUM CGM (San Diego, CA) for one week. Age ( \pm 12 months) and sex-matched controls were also monitored for one week for paired comparison. When recruiting the study population the acceptance rate was $48 \%$ for case children and $36 \%$ for control children. CGM was started only in healthy children with no signs of acute infection. The use of the device was blinded during the study, so the participants were not able to see real-time CGM readings. The participants calibrated the device with self-monitored blood glucose values twice a day with a blood glucose meter according to the manufacturer's instructions. The families were asked to measure the child's SMBG every morning and evening with no special instructions related to meals. All the children were also invited to a five-point OGTT either at the beginning, or at the end of the CGM period. During the OGTT plasma glucose and C-peptide values were analyzed at 0, 30, 60, 90 and $120 \mathrm{~min}$ and a sample for HbA1c measurement was also taken. Body weight and height were measured and ISO-BMI was calculated for every participant at the beginning of the follow-up week [23]. The families were asked to keep food records during the seven days of CGM monitoring with precise timing of all meals and registration of all consumed nourishments. The study physician recruited the participants and installed the CGM device, and also gave guidance on the use of the Dexcom G4 Platinum glucose monitor, SMBG and food records. After the CGM period the physician reviewed the glucose results with the families.

\subsection{Devices}

All participants used the Dexcom G4 Platinum CGM equipment for which good accuracy and good patient experiences have been reported previously [24]. OGTT plasma glucose and C-peptide concentrations were measured in the Oulu University Hospital Laboratory. The hexokinase method was used for plasma glucose and a chemiluminescence method for C-peptide. HbA1c was analyzed with Advia 1800 (Siemens, Munich, Germany). SMBG was measured with the Bayer Contour glucometer (Bayer, Leverkusen, Germany) using the hexokinase based method. 


\subsection{Statistical analyses}

The first $12 \mathrm{~h}$ of the CGM registration were discarded from the analyses to exclude possible false signals during the start of the monitoring. Primary variables given by the Dexcom device were the mean, minimum, maximum, standard deviation (SD), range of glucose values, time spent at or over a glucose value of $7.8 \mathrm{mmol} / \mathrm{l}$, and time spent at or over $11.1 \mathrm{mmol} / \mathrm{l}$. These cut-off values were chosen according to the WHO recommendations for impaired glucose tolerance and diabetes mellitus in an OGTT [25]. Glucose values at or over $7.8 \mathrm{mmol} / \mathrm{l}$ have been shown to be uncommon in healthy individuals [26]. Area under the curve (AUC) for the glucose values was calculated by the trapezoidal rule. The mean amplitude of glycemic excursion (MAGE) was calculated as previously described [27]. In addition, the postprandial glucose values (peak, mean, minimum, maximum, $\mathrm{SD}$ ) were registered from the CGM data $2 \mathrm{~h}$ after each meal for the analyses. Day time was defined as between 6:00 am and midnight, and night time between midnight and 6:00 am. The daily amount of consumed carbohydrates was calculated from the list of consumed nutrients registered by the families (quality and quantity, time of intake) for every meal (breakfast, lunch, dinner and supper) during the study week. Snacks were also included in the total daily carbohydrates. Individual means of all tested parameters during the follow-up week were calculated and the statistical comparison was made with the paired sample t-test between the matched pairs. Spearman's rho was used to analyze the correlation between time since becoming positive for islet autoantibodies and markers of dysglycemia. Statistical significance was set at $p<0.05$. All analyses were performed using IBM SPSS Statistics for Windows (version 22.0; SPSS, Chicago, IL).

\section{Results}

\subsection{Patient baseline characteristics}

The baseline characteristics of the children with a riskassociated class II HLA genotype and multiple islet autoantibodies (cases) and their age- and sex-matched controls with class II HLA-conferred risk for type 1 diabetes mellitus but no autoantibodies are shown in Table 1. Baseline characteristics showed no significant differences between the case and control groups. All ten pairs completed the CGM-follow-up, seven pairs had measured HbA1c values, five pairs had OGTT results and eight pairs completed the food records.

\subsection{CGM and SMBG values}

The mean seven day CGM glucose level was higher in the cases, as were the day and night time CGM values (Table 2). The case children had also higher maximal CGM values and AUC for glucose. Higher variation in the CGM values was observed in the case children, with significant differences in the range $(p=0.032)$, standard deviation $(p=0.040)$ and MAGE $(p=0.031)$. The proportion of time spent at glucose levels $\geqslant 7.8 \mathrm{mmol} / \mathrm{l}$ was higher in the cases, $5.8 \%$ vs. $0.4 \%$, $(95 \% \mathrm{CI}$ of the difference $0.3-10.4, p=0.040$ ), but no difference was observed for the time spent at glucose levels $\geqslant 11.1 \mathrm{mmol} / \mathrm{l}$ $(p=0.152)$.

When comparing the twice daily measured SMBG values the cases had higher mean glucose values in the evening $(p=0.029)$, higher maximum glucose values $(p=0.038)$ and higher glucose variability defined by the standard deviation of all SMBG values $(p=0.020)$; Table 2 .

The clinically most relevant CGM and SMBG values are presented in Fig. 1.

Postprandial glucose values were also analyzed from the CGM data. The only significant difference in postprandial glucose values was observed in the peak glucose after dinner [6.6 mmol/l (SD 0.5) in the cases compared to $6.1 \mathrm{mmol} / \mathrm{l}$ (SD 0.4 ) in the controls; $95 \%$ CI of the difference 0.1 to 1.0 , $p=0.023$ ] (Table 2).

\subsection{HbA1c and OGTT}

The mean HbA1c was $5.7 \%$ (39 $\mathrm{mmol} / \mathrm{mol})$ in the cases and $5.3 \%(34 \mathrm{mmol} / \mathrm{mol})$ in the controls. In paired comparison, the mean difference of HbA1c between the case and the control children was marginally statistically significant $[95 \% \mathrm{CI}$ of the difference $0.01-0.8 \% \quad(0.1-9.0 \mathrm{mmol} / \mathrm{mol}) ; \quad p=0.045]$. Plasma glucose values or serum C-peptide concentrations during the five-point OGTT showed no significant differences between the groups (Table 2).

Table 1 - Baseline characteristics of 10 age- and sex-matched children with increased class II HLA-associated genetic risk for type 1 diabetes mellitus and multiple biochemical islet auto-antibodies (cases) and 10 age- and sex-matched children with class II HLA-associated genetic risk but no autoantibodies (controls).

Cases all

Number of children
Mean age, years (SD)
Boys, $\mathrm{n}$
Mean age at seroconversion, years (SD)
Mean age at multiple $(\geqslant 2)$ autoantibodies, years (SD)
ISO-BMI', $\mathrm{kg} / \mathrm{m}^{2}(\mathrm{SD})$
Mean duration of CGM, days (SD)
Mean number of SMBG values/day, $n$ (SD)

\section{$N=10$}

$9.8(4.1)$

7

$4.2(3.2)$

$6.2(3.9)$

$22.5(3.8)$

$6.9(0.3)$

$2.3(0.4)$

Controls all

ISO-BMI is age and sex-adjusted body mass index reflecting the expected adult BMI [23]. 
Table 2 - Paired comparisons between the children with increased genetic risk for type 1 diabetes mellitus and at least two positive biochemical islet autoantibodies (cases) and their age- and sex-matched controls with genetic risk but no autoantibodies (controls).

\begin{tabular}{|c|c|c|c|c|c|}
\hline CGM & $\mathrm{N}$ & $\begin{array}{l}\text { Cases } \\
\text { mean (SD) }\end{array}$ & $\begin{array}{l}\text { Controls } \\
\text { mean (SD) }\end{array}$ & $\begin{array}{l}95 \% \text { CI of } \\
\text { difference }\end{array}$ & $p$-value \\
\hline Number of pairs & 10 & & & & \\
\hline 7-Day CGM glucose, mmol/l & & $5.4(0.6)$ & $4.7(0.3)$ & 0.1 to 1.1 & 0.018 \\
\hline Day $^{1}$ CGM glucose, $\mathrm{mmol} / \mathrm{l}$ & & $5.4(0.5)$ & $4.9(0.4)$ & 0.04 to 1.0 & 0.036 \\
\hline Night $^{2}$ CGM glucose, $\mathrm{mmol} / \mathrm{l}$ & & $5.3(1.0)$ & $4.4(0.4)$ & 0.1 to 1.7 & 0.026 \\
\hline Maximum CGM glucose, $\mathrm{mmol} / \mathrm{l}$ & & $9.1(2.1)$ & $7.1(0.4)$ & 0.4 to 3.5 & 0.018 \\
\hline Maximum day ${ }^{1}$ CGM glucose, $\mathrm{mmol} / \mathrm{l}$ & & $8.7(1.8)$ & $7.1(0.4)$ & 0.3 to 3.0 & 0.025 \\
\hline Maximum night ${ }^{2}$ CGM glucose, $\mathrm{mmol} / \mathrm{l}$ & & $7.0(1.6)$ & $5.4(0.4)$ & 0.3 to 2.9 & 0.020 \\
\hline Range of CGM glucose, $\mathrm{mmol} / \mathrm{l}$ & & $5.7(2.3)$ & $3.9(0.7)$ & 0.2 to 3.5 & 0.032 \\
\hline Range of day ${ }^{1}$ CGM glucose, $\mathrm{mmol} / \mathrm{l}$ & & $5.3(2.1)$ & $3.8(0.7)$ & 0.1 to 3.1 & 0.043 \\
\hline Range of night ${ }^{2}$ CGM glucose, $\mathrm{mmol} / \mathrm{l}$ & & $2.8(1.3)$ & $1.7(0.3)$ & 0.2 to 2.0 & 0.025 \\
\hline 7-Day CGM glucose values SD, mmol/l & & $1.2(0.5)$ & $0.8(0.2)$ & 0.02 to 0.7 & 0.040 \\
\hline Day $^{1}$ CGM glucose values SD, $\mathrm{mmol} / \mathrm{l}$ & & $3.6(1.4)$ & $1.9(0.4)$ & 0.6 to 2.7 & 0.007 \\
\hline Night $^{2}$ CGM glucose values SD, $\mathrm{mmol} / \mathrm{l}$ & & $0.7(0.4)$ & $0.4(0.1)$ & 0.1 to 0.6 & 0.020 \\
\hline CGM glucose, $\%$ Time $\geqslant 7.8 \mathrm{mmol} / \mathrm{l}$ & & $5.8(7.0)$ & $0.4(0.4)$ & 0.3 to 10.4 & 0.040 \\
\hline CGM glucose, \%Time $\geqslant 11.1 \mathrm{mmol} / \mathrm{l}$ & & $0.8(1.5)$ & $0.0(0.0)$ & -0.3 to 1.9 & 0.152 \\
\hline CGM glucose AUC, $\mathrm{mmol} / \mathrm{min} / \mathrm{l}$ & & $127.1(13.2)$ & $113.5(7.1)$ & 1.8 to 25.4 & 0.028 \\
\hline CGM glucose AUC day ${ }^{1}, \mathrm{mmol} / \mathrm{min} / \mathrm{l}$ & & $96.2(8.7)$ & $88.0(5.7)$ & 0.6 to 15.9 & 0.038 \\
\hline CGM glucose AUC night ${ }^{2}, \mathrm{mmol} / \mathrm{min} / \mathrm{l}$ & & $30.9(5.6)$ & $25.5(3.1)$ & 0.6 to 10.1 & 0.031 \\
\hline 7-Day CGM glucose MAGE, mmol/l & & $1.2(0.5)$ & $0.8(0.2)$ & 0.04 to 7.5 & 0.031 \\
\hline \multicolumn{6}{|l|}{$\mathrm{SMBG}, \mathrm{mmol} / \mathrm{l}$} \\
\hline Number of pairs & 10 & & & & \\
\hline 7-Day SMBG glucose, $\mathrm{mmol} / \mathrm{l}$ & & $5.3(0.5)$ & $5.0(0.3)$ & -0.2 to 0.7 & 0.227 \\
\hline Morning ${ }^{3}$ SMBG glucose, $\mathrm{mmol} / \mathrm{l}$ & & $4.9(0.6)$ & $4.8(0.4)$ & -0.6 to 0.6 & 0.899 \\
\hline Evening $^{3}$ SMBG glucose, $\mathrm{mmol} / \mathrm{l}$ & & $5.8(0.6)$ & $5.3(0.3)$ & 0.1 to 1.0 & 0.029 \\
\hline Maximum SMBG glucose, $\mathrm{mmol} / \mathrm{l}$ & & $8.1(1.7)$ & $6.6(0.9)$ & 0.1 to 2.9 & 0.038 \\
\hline 7-Day SMBG glucose SD, mmol/l & & $1.3(0.5)$ & $0.8(0.2)$ & 0.1 to 0.8 & 0.020 \\
\hline \multicolumn{6}{|l|}{ HbA1c } \\
\hline Number of pairs & 7 & & & & \\
\hline $\mathrm{HbA} 1 \mathrm{c} \%$ & & $5.7(0.3)$ & $5.3(0.2)$ & 0.01 to 0.8 & 0.045 \\
\hline $\mathrm{HbA} 1 \mathrm{c} \mathrm{mmol} / \mathrm{mol}$ & & $39(4)$ & $34(2)$ & 0.1 to 9 & \\
\hline \multicolumn{6}{|l|}{ OGTT } \\
\hline Number of pairs & 5 & & & & \\
\hline 0-Min plasma glucose, $\mathrm{mmol} /$ & & $5.2(0.3)$ & $5.0(0.1)$ & -0.2 to 0.6 & 0.266 \\
\hline 30-Min plasma glucose, $\mathrm{mmol} / \mathrm{l}$ & & $8.4(1.6)$ & $7.3(0.9)$ & -0.8 to 3.0 & 0.190 \\
\hline 60-Min plasma glucose, $\mathrm{mmol} / \mathrm{l}$ & & $6.9(2.7)$ & $7.0(2.0)$ & -5.1 to 4.7 & 0.923 \\
\hline 90-Min plasma glucose, $\mathrm{mmol} / \mathrm{l}$ & & $6.7(1.3)$ & $6.3(1.7)$ & -2.6 to 3.6 & 0.702 \\
\hline 120-Min plasma glucose, $\mathrm{mmol} / \mathrm{l}$ & & $5.9(1.1)$ & $5.7(1.3)$ & -1.2 to 1.4 & 0.814 \\
\hline OGTT plasma glucose AUC, $\mathrm{mmol} / \mathrm{min} / \mathrm{l}$ & & $27.5(4.9)$ & $26.0(4.9)$ & -8.1 to 11.1 & 0.684 \\
\hline 0-Min serum C-peptide, $\mathrm{nmol} / \mathrm{l}$ & & $0.35(0.12)$ & $0.27(0.11)$ & -0.08 to 0.23 & 0.246 \\
\hline 30-Min serum C-peptide, $\mathrm{nmol} / \mathrm{l}$ & & $1.17(0.49)$ & $1.09(0.50)$ & -0.51 to 0.67 & 0.713 \\
\hline 60-Min serum C-peptide, $\mathrm{nmol} / \mathrm{l}$ & & $1.19(0.49)$ & $1.39(0.74)$ & -0.69 to 0.30 & 0.329 \\
\hline 90-Min serum C-peptide, $\mathrm{nmol} / \mathrm{l}$ & & $1.30(0.52)$ & $1.49(0.91)$ & -0.96 to 0.60 & 0.553 \\
\hline 120-Min serum C-peptide, $\mathrm{nmol} / \mathrm{l}$ & & $1.30(0.57)$ & $1.26(0.71)$ & -0.36 to 0.45 & 0.768 \\
\hline OGTT serum C-peptide AUC, $\mathrm{nmol} / \mathrm{min} / \mathrm{l}$ & & $4.49(1.77)$ & $4.73(2.47)$ & -1.92 to 1.45 & 0.719 \\
\hline \multicolumn{6}{|l|}{ Food records } \\
\hline \multicolumn{6}{|l|}{$\begin{array}{l}\text { Meal specific carbohydrate amounts and postprandial } \\
\text { CGM glucose values } 60-120 \text { min after the meal }\end{array}$} \\
\hline Number of pairs & 8 & & & & \\
\hline \multicolumn{6}{|l|}{ Breakfast } \\
\hline Carbohydrates, g & & $38.7(8.2)$ & $41.0(5.8)$ & -8.9 to 4.3 & 0.433 \\
\hline Mean postprandial CGM glucose, $\mathrm{mmol} / \mathrm{l}$ & & $5.7(1.1)$ & $4.9(0.3)$ & -0.3 to 1.7 & 0.122 \\
\hline Maximum postprandial CGM glucose, mmol/l & & $7.5(2.0)$ & $6.1(0.4)$ & -0.3 to 3.2 & 0.086 \\
\hline \multicolumn{6}{|l|}{ Lunch } \\
\hline Carbohydrates, g & & $49.6(10.4)$ & $52.0(8.9)$ & -14.5 to 9.5 & 0.641 \\
\hline Mean postprandial CGM glucose, $\mathrm{mmol} / \mathrm{l}$ & & $5.2(0.6)$ & $5.1(0.3)$ & -0.4 to 0.8 & 0.539 \\
\hline Maximum postprandial CGM glucose, $\mathrm{mmol} / \mathrm{l}$ & & $6.6(1.0)$ & $6.2(0.5)$ & -0.7 to 1.5 & 0.444 \\
\hline
\end{tabular}




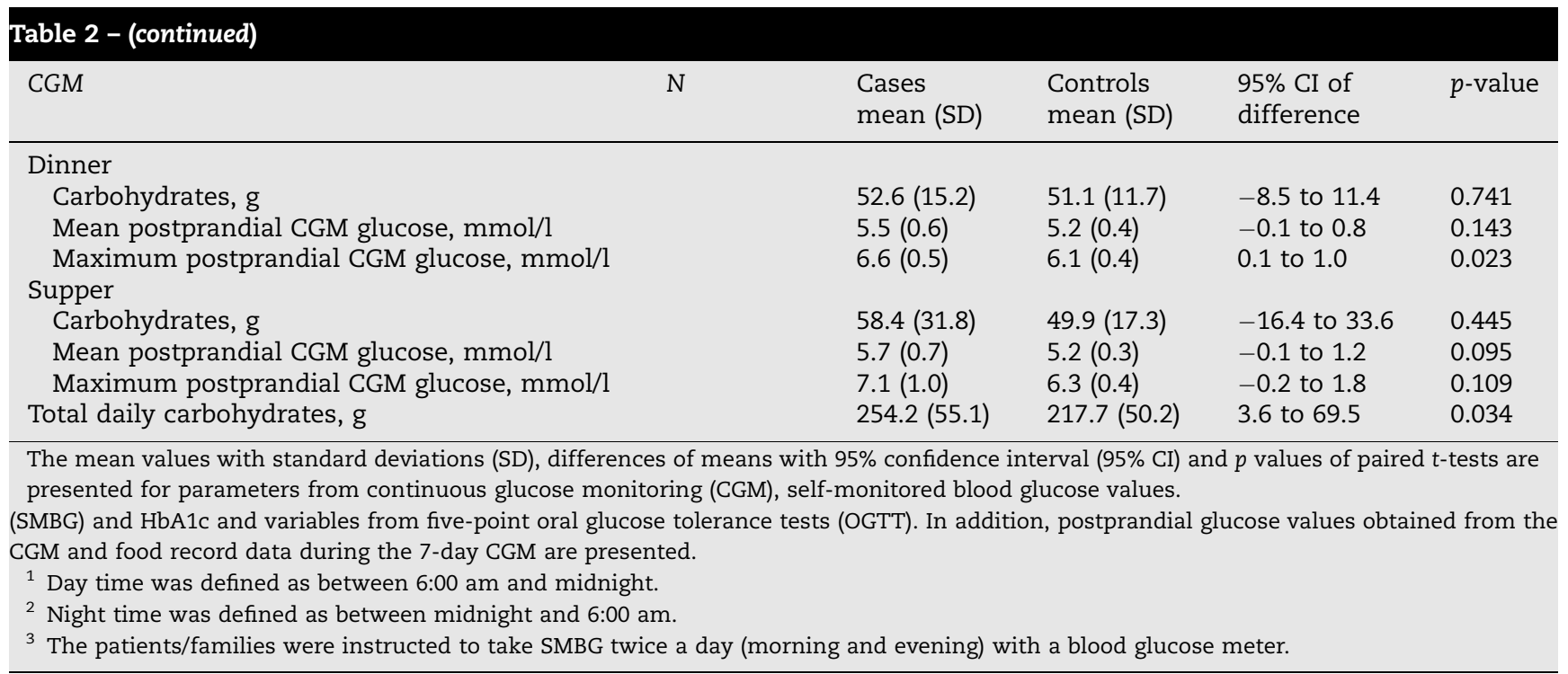

\subsection{The time since seroconversion and markers of dysglycemia}

We also analyzed possible correlations between the time since becoming positive for islet autoantibodies and various markers of dysglycemia (HbA1c, the mean CGM glucose, the mean AUC for CGM glucose, 7-day CGM glucose SD, MAGE, and the time spent $\geqslant 7.8 \mathrm{mmol} / \mathrm{l}$ ) but no correlations were found.

\subsection{Food records}

The amount of carbohydrates ingested showed no significant differences in any of the meals between the cases and controls, but the total amount of daily carbohydrates including snacks between the main meals was slightly higher in the cases [254.2 g (SD 55.1) compared to the controls, $217.7 \mathrm{~g}$ (SD 50.2); 95\% CI of the difference 3.6-69.4; $p=0.034$ ] (Table 2).

\section{Discussion}

This study demonstrates that asymptomatic children with preclinical type 1 diabetes mellitus defined by positivity for multiple biochemical islet autoantibodies have higher glucose levels and higher glycemic variation when monitored with CGM in comparison to autoantibody-negative controls. Especially, the evening glucose values detected by CGM and also by SMBG were higher in these children than in the controls.

In the CGM analysis the proportion of time spent at a glucose level at or over $7.8 \mathrm{mmol} / \mathrm{l}$ during the 7-day follow-up period was $5.8 \%$ in the islet autoantibody-positive children compared to only $0.4 \%$ in the autoantibody-negative controls. Recently, CGM data was also analyzed among autoantibody positive children $(n=14)$ and autoantibody negative controls $(n=9)$ in the DAISY Study [16]. According to their findings, autoantibody-positive children spent as much as $18 \%$ of their time at or over the cut-off value of $7.8 \mathrm{mmol} / \mathrm{l}$ [16] and autoantibody-negative control children with increased
HLA-conferred risk also spent as much as $9 \%$ over the cutoff limit. Previously Fox et al. studied 74 healthy individuals without diabetes aged 9-65 years with CGM, showing that only $0.4 \%$ of the follow-up time was spent over the cut-off $7.8 \mathrm{mmol} / \mathrm{l}[26]$, which is exactly the same as seen in the control group in our study. According to our study the cut-off $7.8 \mathrm{mmol} / \mathrm{l}$ could be a more specific marker for detection of upcoming disease than previously reported by Steck et al. [16]. Our findings are further supported by the results of van Dalem et al. who also reported that increased time spent $\geqslant 7.8 \mathrm{mmol} / \mathrm{l}$ during CGM may be useful in detecting early dysglycemia in preclinical type 1 diabetes mellitus [18].

To our knowledge this is the first study to report increased evening glucose concentrations in children with preclinical type 1 diabetes mellitus. Higher CGM values postprandially after dinner and higher SMBG values in the evening were observed (Table 2). This observation is in good accordance with the clinical experience showing that young children with established type 1 diabetes mellitus need higher basal insulin doses in the evening [28]. SMBG samples were obtained with no instructions related to meals, possibly interfering with pairwise comparison. The value of evening glucose measurements in the prediction of clinical diagnosis remains to be assessed further in more detail and in larger series of subjects with preclinical type 1 diabetes mellitus. OGTTs or mixed meal tolerance tests performed in the evening could show different results than the standard tests performed in the morning after overnight fasting. New studies are needed to explore this hypothesis.

Rather surprisingly, the postprandial CGM glucose values after breakfast and lunch were not different between our case and control children. This result is, however, in line with the lack of significant differences in plasma glucose values between the case and the control children during the OGTT. On the basis of these observations it seems that increased variation over $24 \mathrm{~h}$ and slightly elevated mean CGM glucose levels occur in the preclinical stage of type 1 diabetes mellitus before postprandial changes. 

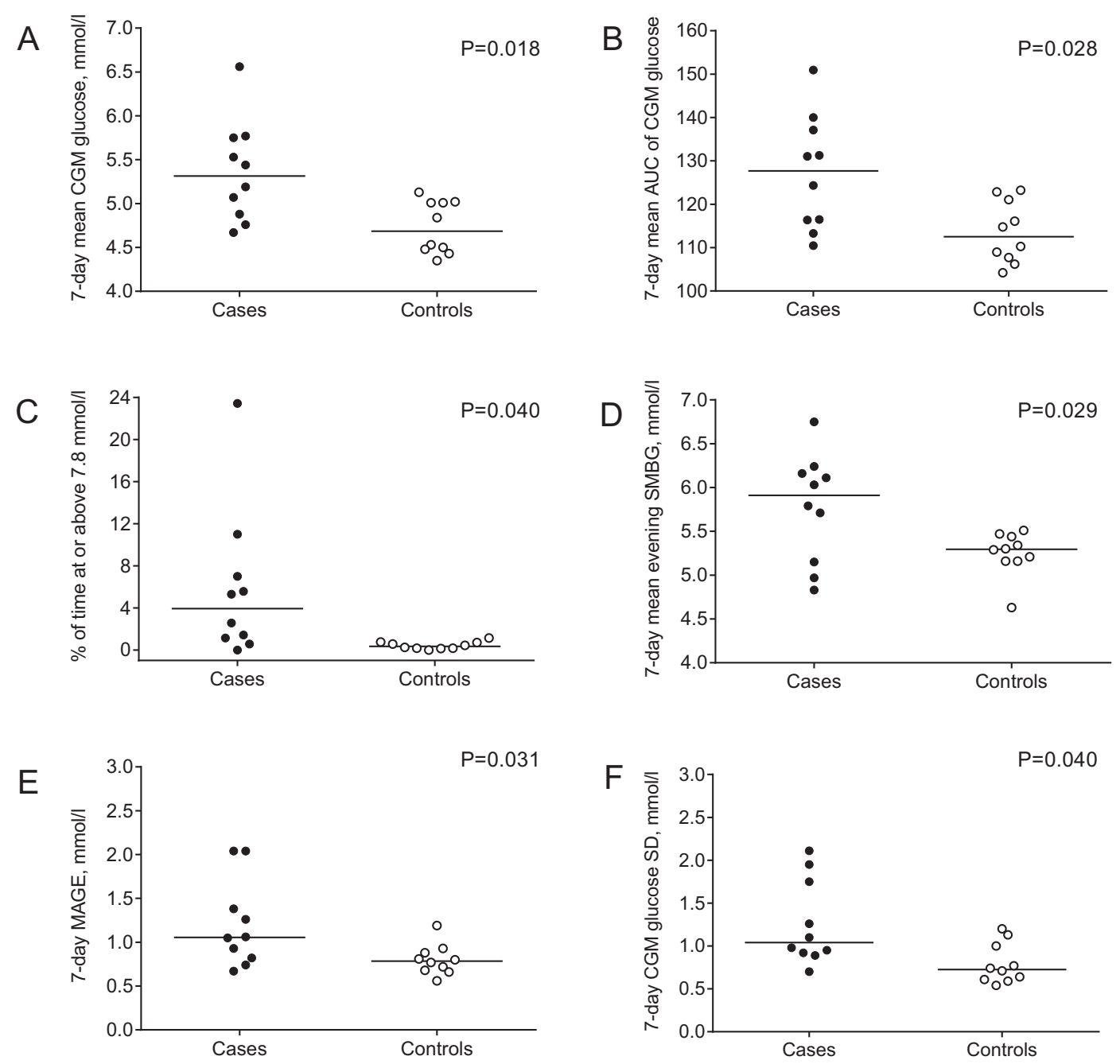

Fig. 1 - Dot-plot charts of clinically relevant differences in continuous glucose monitoring (CGM) and self-monitored blood glucose (SMBG) in asymptomatic children with multiple $(\geqslant 2)$ islet autoantibodies (cases) and age and sex-matched autoantibody-negative controls. The mean CGM glucose (A) and area under the curve (AUC, $\mathrm{mmol} / \mathrm{min} / \mathrm{l}, \mathrm{B}$ ) during the 7-day follow-up were significantly higher in the case group. The time spent at or above the cut-off glucose value of $7.8 \mathrm{mmol} / \mathrm{l}$ measured with CGM (C), and evening SMBG values (D) were higher in the cases. Increased variation in the CGM glucose values characterized by mean amplitude of glycemic excursion (MAGE, E) and overall standard deviation (SD) during 7-day CGM (F) was observed in the case children compared to the controls.

HbA1c values showed significant differences between the case and control children despite the small number of study subjects included in this series. The utility of monitoring $\mathrm{HbA1c}$ in the prediction of the timing of type 1 diabetes mellitus has been implicated by previous follow-up studies in children at risk for overt type 1 diabetes mellitus [12,29].

In the current small series plasma glucose concentrations in OGTT were not different between the case and control children. The use of OGTT in the prediction of type 1 diabetes mellitus has been widely studied, but the sensitivity of the test has proven rather disappointing $[9,13]$. Randomly taken plasma glucose has also been assessed in studies aimed at early recognition of type 1 diabetes mellitus with high specificity but with poor sensitivity [9]. In the current study SMBG values were higher when considering the mean and maximal concentrations, and also the variation in SMBG levels. The poor sensitivity previously reported was observed when glucose samples were taken every 3-6 months, and this could most likely be improved simply by increasing the number of SMBG measurements and shortening the intervals between the measurements. It could be feasible to obtain several daily SMBG values over a short period of time, e.g. during one week, and analyze the predictive characteristics of this data.

One shortcoming of the present study is that only five of the control children accepted to undergo an OGTT and seven to give a sample for HbA1c analysis. One child in each group completed the food record inadequately. Especially the OGTT parameters may be misleading due to the small study population. Families whose child refused to undergo the tests considered it too time consuming or inconvenient for the participant. There is wide variation in time from detection of autoantibodies to clinical type 1 diabetes mellitus and emergence of dysglycemia is a rather late phenomenon before diagnosis. It is possible that our OGTT series included 
case children who still were at the early stage of preclinical diabetes mellitus and therefore no differences could be seen between our cases and the controls.

When analyzing the relationship between the time since becoming positive for islet autoantibodies and various markers of dysglycemia no significant correlations were found. It is difficult to draw firm conclusions because of the small sample size of our study. However, long-term follow-up of subjects with multiple islet autoantibodies have shown that clinical diabetes is diagnosed at a constant rate over long time periods [5]. Some subjects with persistent islet autoimmunity are rapid progressors and others may remain normoglycemic for years before progressing to diabetes. Thus it would be logical that the time from seroconversion does not necessarily correlate with the markers of dysglycemia.

Monitoring of glucose metabolism may be useful in the identification of emerging type 1 diabetes mellitus in highrisk children, as suggested previously [16-18], and may help the family to prepare for the diagnosis. It is important to note that early diagnosis of type 1 diabetes mellitus prevents diabetic ketoacidosis at disease onset and thereby reduces the burden for the patient and their family and shortens the initial hospitalization as well [30]. The overall prevalence of diabetic ketoacidosis among children with newly onset type 1 diabetes mellitus in Finland is approximately 20\% [31], but significantly lower in children with prospective follow-up before the onset [30]. It is also possible that participation in preclinical follow-up studies and awareness of positivity for islet autoantibodies induces stress in the families of children with high risk for progression to type 1 diabetes mellitus, and in motivated subjects, CGM may provide further information about the glycemic status and relief when interpreted together with the study personnel. Furthermore, reliable tools are needed for monitoring glucose metabolism during the preclinical stage of type 1 diabetes mellitus in secondary prevention studies aimed at postponing or even preventing the disease by trying to preserve the endogenous insulin secretion [32].

In conclusion, these results show that CGM, HbA1c and evening SMBG measurements may be useful monitoring tools for emerging dysglycemia in children with preclinical type 1 diabetes mellitus.

\section{Funding}

This work was supported by the following grants. International: JDRF International (grants 4-1998-274, 4-1999-731, 4-2001-435); European Union (grant BMH4-CT98-3314); Novo Nordisk Foundation. Finland: Academy of Finland (Centre of Excellence in Molecular Systems Immunology and Physiology Research 2012-2017, Decision No. 250114); TEKES National Technology Agency of Finland; Special Research Funds for University Hospitals in Finland; Finnish Office for Health Technology Assessment; Diabetes Research Foundation, Finland; Sigrid Juselius Foundation; Emil Aaltonen Foundation; Jalmari and Rauha Ahokas Foundation; Signe and Ane Gyllenberg Foundation; the Research Foundation of Orion Corporation; Foundation for Pediatric Research; Alma and KA Snellman Foundation; Päivikki and Sakari
Sohlberg Foundation and Finnish Cultural Foundation, North Ostrobothnia Regional Fund.

\section{Duality of interest}

The authors declare that there is no duality of interest associated with this manuscript.

\section{Contribution statement}

$\mathrm{OH}$ had full access to all of the data in the study and takes responsibility for the integrity of the data and the accuracy of the data analysis. OH, JI, MK and RV contributed to the study concept and design. OH, JI, MK and RV contributed to the acquisition of the data. $\mathrm{OH}, \mathrm{TP}, \mathrm{PT}, \mathrm{MK}$ and RV contributed to the analysis and interpretation of the data. OH, TP, PT, MK and RV drafted the manuscript. OH, TP, PT, JI, MK and RV critically revised the manuscript for important intellectual content. TP was responsible for the statistical analysis. OH, TP, PT, JI, MK and RV provided administrative, technical or material support. RV supervised the study. All authors read and approved the final version of the manuscript.

\section{Conflict of interest}

The authors state no potential conflicts of interest.

\section{Acknowledgements}

We thank the dedicated personnel of the DIPP study in Oulu, Tampere and Turku; and the study children and their families for their essential contribution.

\section{R E F E R E N C E S}

[1] DIAMOND Project Group. Incidence and trends of childhood Type 1 diabetes worldwide 1990-1999. Diabet Med 2006;8:857-66.

[2] Patterson CC, Gyurus E, Rosenbauer J, Cinek O, Neu A, Schober E, et al. Trends in childhood type 1 diabetes incidence in Europe during 1989-2008: evidence of nonuniformity over time in rates of increase. Diabetologia 2012;8:2142-7.

[3] Harjutsalo V, Sjoberg L, Tuomilehto J. Time trends in the incidence of type 1 diabetes in Finnish children: a cohort study. Lancet 2008;9626:1777-82.

[4] Tarn AC, Thomas JM, Dean BM, Ingram D, Schwarz G, Bottazzo GF, et al. Predicting insulin-dependent diabetes. Lancet 1988;8590:845-50.

[5] Ziegler AG, Rewers M, Simell O, Simell T, Lempainen J, Steck A, et al. Seroconversion to multiple islet autoantibodies and risk of progression to diabetes in children. JAMA 2013;23:2473-9.

[6] Siljander HT, Simell S, Hekkala A, Lahde J, Simell T, Vahasalo $\mathrm{P}$, et al. Predictive characteristics of diabetes-associated autoantibodies among children with HLA-conferred disease susceptibility in the general population. Diabetes 2009;12:2835-42.

[7] Sosenko JM, Skyler JS, Krischer JP, Greenbaum CJ, Mahon J, Rafkin LE, et al. Glucose excursions between states of 
glycemia with progression to type 1 diabetes in the diabetes prevention trial-type 1 (DPT-1). Diabetes 2010;10:2386-9.

[8] Siljander HT, Hermann R, Hekkala A, Lahde J, Tanner L, Keskinen $\mathrm{P}$, et al. Insulin secretion and sensitivity in the prediction of type 1 diabetes in children with advanced betacell autoimmunity. Eur J Endocrinol 2013;4:479-85.

[9] Helminen O, Aspholm S, Pokka T, Ilonen J, Simell O, Veijola R, et al. OGTT and random plasma glucose in the prediction of type 1 diabetes and time to diagnosis. Diabetologia 2015;8:1787-96.

[10] Beer SF, Heaton DA, Alberti KG, Pyke DA, Leslie RD. Impaired glucose tolerance precedes but does not predict insulindependent diabetes mellitus: a study of identical twins. Diabetologia 1990;8:497-502.

[11] Tarn AC, Smith CP, Spencer KM, Bottazzo GF, Gale EA. Type I (insulin dependent) diabetes: a disease of slow clinical onset? Br Med J 1987;6568:342-5.

[12] Helminen O, Aspholm S, Pokka T, Hautakangas MR, Haatanen N, Lempainen J, et al. HbA1c predicts time to diagnosis of type 1 diabetes in children at risk. Diabetes 2015;5:1719-27.

[13] Sosenko JM, Skyler JS, Mahon J, Krischer JP, Beam CA, Boulware DC, et al. The application of the diabetes prevention trial-type 1 risk score for identifying a preclinical state of type 1 diabetes. Diabetes Care 2012;7:1552-5.

[14] Deiss D, Bolinder J, Riveline JP, Battelino T, Bosi E, TubianaRufi N, et al. Improved glycemic control in poorly controlled patients with type 1 diabetes using real-time continuous glucose monitoring. Diabetes Care 2006;12:2730-2.

[15] Juvenile Diabetes Research Foundation Continuous Glucose Monitoring Study Group, Tamborlane WV, Beck RW, Bode BW, Buckingham B, Chase HP, et al. Continuous glucose monitoring and intensive treatment of type 1 diabetes. $\mathrm{N}$ Engl J Med 2008;14:1464-76.

[16] Steck AK, Dong F, Taki I, Hoffman M, Klingensmith GJ, Rewers MJ. Early hyperglycemia detected by continuous glucose monitoring in children at risk for type 1 diabetes. Diabetes Care 2014;7:2031-3.

[17] Brancato D, Saura G, Fleres M, Ferrara L, Scorsone A, Aiello V, et al. Prognostic accuracy of continuous glucose monitoring in the prediction of diabetes mellitus in children with incidental hyperglycemia: receiver operating characteristic analysis. Diabetes Technol Ther 2013;7:580-5.

[18] Van Dalem A, Demeester S, Balti EV, Decochez K, Weets I, Vandemeulebroucke E, et al. Relationship between glycaemic variability and hyperglycaemic clamp-derived functional variables in (impending) type 1 diabetes. Diabetologia 2015;12:2753-64.

[19] Steffes MW, Sibley S, Jackson M, Thomas W. Beta-cell function and the development of diabetes-related complications in the diabetes control and complications trial. Diabetes Care 2003;3:832-6.

[20] Parikka V, Nanto-Salonen K, Saarinen M, Simell T, Ilonen J, Hyoty $\mathrm{H}$, et al. Early seroconversion and rapidly increasing autoantibody concentrations predict prepubertal manifestation of type 1 diabetes in children at genetic risk. Diabetologia 2012;7:1926-36.

[21] Nanto-Salonen K, Kupila A, Simell S, Siljander H, Salonsaari T, Hekkala A, et al. Nasal insulin to prevent type 1 diabetes in children with HLA genotypes and autoantibodies conferring increased risk of disease: a double-blind, randomised controlled trial. Lancet 2008;9651:1746-55.

[22] Hermann R, Knip M, Veijola R, Simell O, Laine AP, Akerblom HK, et al. Temporal changes in the frequencies of HLA genotypes in patients with Type 1 diabetes-indication of an increased environmental pressure? Diabetologia 2003;3:420-5.

[23] Berhan YT, Mollsten A, Carlsson A, Hogberg L, Ivarsson A, Dahlquist G. Five-region study finds no evidence of undiagnosed type 2 diabetes in Swedish 11- to 13-year-olds. Acta Paediatr 2014;10:1078-82.

[24] Matuleviciene V, Joseph JI, Andelin M, Hirsch IB, Attvall S, Pivodic A, et al. A clinical trial of the accuracy and treatment experience of the Dexcom G4 sensor (Dexcom G4 system) and Enlite sensor (guardian REAL-time system) tested simultaneously in ambulatory patients with type 1 diabetes. Diabetes Technol Ther 2014;11:759-67.

[25] Greenbaum CJ, Cuthbertson D, Krischer JPDisease Prevention Trial of Type I Diabetes Study Group. Type I diabetes manifested solely by 2 -h oral glucose tolerance test criteria. Diabetes 2001;2:470-6.

[26] Juvenile Diabetes Research Foundation Continuous Glucose Monitoring Study Group, Fox LA, Beck RW, Xing D. Variation of interstitial glucose measurements assessed by continuous glucose monitors in healthy, nondiabetic individuals. Diabetes Care 2010;6:1297-9.

[27] Marling CR, Shubrook JH, Vernier SJ, Wiley MT, Schwartz FL. Characterizing blood glucose variability using new metrics with continuous glucose monitoring data. J Diabetes Sci Technol 2011;4:871-8.

[28] Nicolajsen T, Samuelsson A, Hanas R. Insulin doses before and one year after pump start: children have a reversed dawn phenomenon. J Diabetes Sci Technol 2012;3:589-94.

[29] Stene LC, Barriga K, Hoffman M, Kean J, Klingensmith G, Norris JM, et al. Normal but increasing hemoglobin A1c levels predict progression from islet autoimmunity to overt type 1 diabetes: Diabetes Autoimmunity Study in the Young (DAISY). Pediatr Diabetes 2006;5:247-53.

[30] Elding Larsson H, Vehik K, Bell R, Dabelea D, Dolan L, Pihoker C, et al. Reduced prevalence of diabetic ketoacidosis at diagnosis of type 1 diabetes in young children participating in longitudinal follow-up. Diabetes Care 2011;11:2347-52.

[31] Hekkala A, Reunanen A, Koski M, Knip M, Veijola RFinnish Pediatric Diabetes Register. Age-related differences in the frequency of ketoacidosis at diagnosis of type 1 diabetes in children and adolescents. Diabetes Care 2010;7:1500-2.

[32] Skyler JS. Prevention and reversal of type 1 diabetes-past challenges and future opportunities. Diabetes Care 2015;6:997-1007. 